\title{
LOS ROMANCES DE MALMARIDADA A LA LUZ DE CÓDIGOS CULTOS.
}

\author{
José Carlos Terradas ${ }^{1}$
}

\section{RESUMEN}

Los romances de malmaridada españoles, a diferencia de los arquetípicos franceses, más que presentar una unión matrimonial desafortunada, ahondan de manera subrepticia en las características del marido, la esposa y el amante, y en la situación conyugal en sí. Lo que podría ser sólo una historia de hombres burlados por sus mujeres se transforma en un profundo entramado psicológico que explica, a través de palabras claves o indiciales, las causas del adulterio. Investigadores de principios y mediados del XX cubrieron con la ética patriarcal los rincones oscuros de esta casa y centraron sus estudios en el castigo de la mujer, supuestamente justo. No indagaron en la reiteración, nada casual, de ciertas secuencias y palabras, cuya continuidad temporal no sólo las reivindica sino que las focaliza como imprescindibles. Se trata de aprehender los romances de malmaridada como un todo que, más allá de la artificiosidad de un final frecuentemente represor, establece una crítica patente contra los matrimonios asimétricos.

Palabras clave: malmaridada, romance, adulterio, virginidad, Edad Media.

\begin{abstract}
.
The Spanish romances of malmaridada, unlike the French originals, more than presenting the unfortunate matrimonial union, go deeply into the husband's, the wife's and the lover's characteristics, and into the whole married situation in a surreptitious manner. What could be just a story of men betrayed by their women becomes into a profound psychological framework that explains, thru key words or a code, the causes of the adultery. Twenty-century scholars hid with the patriarchal ethic the dark nooks of this home and focused their research on the woman's punishment, supposedly just. They did not investigate the repetition, far from accidental, of certain sequences and words, whose continuity in time, not only vindicates them, but also, determines them as indispensable. We are to apprehend the romances of
\end{abstract}

1 Florida International University (FIU). USA. E-mail: jcterradas@yahoo.com. 
malmaridada as a whole that, beyond an ending frequently oppressive, state conspicuous judgment against asymmetrical marriages.

Key Words: malmaridada, adultery, ballad, virginity, Middle Age.

Es difícil encontrar una recopilación romanceril donde no se incluya "Blanca Niña" o "Albaniña": su belleza, su final trágico, la tensión lograda por las preguntas y respuestas entre la mujer y el marido, lo hacen imprescindible para cualquier colección de romances. En su estudio sobre el origen de esta obra, William J. Entwistle afirma: "El cuento de la Blancaniña nació en Francia, allá en el siglo XIII. Era el conocido fabliau de Le chavalier a la robe vermeille, que se leen en el Recueil général des fabliaux, de Montaiglon et Renaud y en otras colecciones". Esta composición francesa trataba básicamente de lo mismo que cuenta el romance español: "Un vavassor rico se ausenta de la casa porque tiene un pleito que concluir en otra ciudad. Llega el chevalier, vestido con su capa bermeja, y la mujer del vasallo le acoge amistosamente". ${ }^{2}$ Los problemas sobrevienen cuando el marido arriba de improviso y, para su sorpresa, encuentra novedades en la casa. La mujer logra engañarlo y también que el caballero salga ileso. Desenlace que, según dicho estudioso, no se da en la versión romanceril española. ${ }^{3}$ El poema español se distingue del modelo arquetípico francés y de las baladas extranjeras posteriores por su desenlace conmovedor: "la mujer castellana no pide perdón; reconoce su falta y pide la muerte: he aquí -continúa el erudito- una desviación mínima que ha transformado un fabliau vulgar en un romance altamente trágico."

La bella malmaridada es quizá el romance más famoso y reproducido. Difícil sería encontrar un poeta del siglo XVI que desconociera sus versos. Tantas veces fue glosado que en el Cancionero de Amberes aparece una copla contra los glosadores. ${ }^{4}$ Sobre su ori-

\footnotetext{
2 Entwistle, William J.: “Blanca Niña”, Revista de Filología Hispánica, I (1939), p. 159.

3 El cuento medieval derivó en una canción francesa popular, también medieval. Las versiones que recoge de ésta E. Rolland -nos dice Entwistle- presentan al caballero con espada, lo cual indica que son tardías. Anteriormente llevaría lanza, "indumentaria del siglo XV, cuando los caballeros solían andar de visita con caballo y lanza.” En el romance de Blanca Niña se conserva dicha arma: “CCúya es aquella lanza / desde aquí la veo yo?”, también en el visé danés de Hurtige Svar. Por esto, infiere Entwistle, debió existir una versión francesa anterior a las recogidas por Rolland. Versión que, además, presentaría una alusión a las llaves dado que el romance español y el visé danés la conservan. En el fabliau y en las baladas el interés parece desplazarse hacia la habilidad para mentir de la mujer, hasta el punto que el visé danés contiene este verso: “-Hermano, si tú sabes más preguntas, / yo sabré darte más contestaciones”. La mujer se muestra como diestra embaucadora, puede desvirtuar las pruebas más evidentes de su infidelidad. Entwistle, William J.: "Blanca Niña”, Revista de Filología Hispánica, I (1939), p. 163.

4 Sus últimos versos dicen así:

¡Oh bella malmaridada,

a qué manos has venido!

Mal casada y mal trovada,

de los poetas tratada

peor que de tu marido.

La afición a este romance llega a tal extremo que Francisco Rodríguez Marín, después de darnos una extensa lista de poetas españoles que lo han intervenido a su manera, nos dice que es inútil seguir citando nombres. La manía de glosar La bella... no se limitaba a España:
} 
gen varios estudiosos se han pronunciado sin llegar a respuesta concreta. Francisco Asenjo Barbieri nos dice que desconoce si la composición tuvo en su inicio el modelo de villancico o de romance ya que de las dos formas era muy conocido. ${ }^{5}$ Tanto este estudioso como Francisco Rodríguez Marín refieren que su historia parece estar basada en una mujer, una señora llamada Peralta, que vivió a finales del siglo XV o principios de XVI. ${ }^{6}$ Ramón Menéndez Pidal también se pronunció sobre el asunto en su Romancero Hispánico:

El adulterio no es tratado en el romancero bajo forma cómica [...] las canciones de la malcasada que en Francia toman en broma al engañado marido, producen en España el romance de La bella malmaridada, donde ella pide a su esposo la muerte que merecida tiene. Derivada de un fabliau del siglo XIII [...] contiene una serie de preguntas hechas por el marido, el padre o el hermano a la mujer sorprendida con su amante, preguntas reiteradas con un propósito cómico, pues las burdas respuestas de la mujer satisfacen al preguntante; sólo en la versión española Blanca sois, señora mía [...] las preguntas del marido [...] toman un sesgo fulmíneo y condenatorio, convirtiendo la canción cómica, de sal gorda, en un romance altamente trágico. ${ }^{7}$

La composición de malmaridada, al llegar a una nueva tierra, con un código moral diferente, se adaptaría al uso y costumbres de sus nuevos dueños y forjadores, aceptando cambios en sus líneas a fin de sobrevivir. El realismo que le atribuían Barbieri y Rodríguez Marín al poema es recogido y ampliado por Menéndez Pidal. Al darle Castilla un final ético, ocasiona dos cosas: 1) cambia radicalmente la dirección que llevaba antiguamente el poema: irrisión del marido burlado deviene en castigo de los amantes, restauración de la honra; y 2) opone formas de comportamiento interpersonal

Gil Vicente en su tragicomedia Fragoa d'Amor representada en Evora a los desposorios del rey don Juan III con la reina doña Catalina en 1525, introduce un negro que dice venir de Tordesillas, el cual canta:

La bella mal maruvada

de linde que a mí ve,

vejo-te nojada,

dice tu razao puruqué

Véase Rodríguez Marín, Francisco: “Apéndice II”, Viaje del Parnaso, Madrid, C. Bermejo (Ed.), 1935, pp. 452-454 y también José J. Labrador Herraiz y Ralph DiFranco: "Continuidad de la poesía del XV en canciones del XVI", Prologus Baenensis, No 1, 1-52. 30 de octubre de 2006. http://www.juanalfonsodebaena.org/ ACTAS\%20LABRADOR.htm, págs. 34-42.

5 Sin embargo, apunta que "es muy de notar que los cuatro primeros versos de él constituyen una copla, en la cual son consonantes el tercero con el primero y el cuarto con el segundo, siguiendo después la composición en la ordinaria forma de romance [...] irregularidad que induce a sospechar que tal vez la primitiva composición fue villancico de cuatro versos, y que sobre éstos se hizo el romance.” Barbieri, Francisco Asenjo: Cancionero musical español de los siglos XV y XVI, Buenos Aires, Editorial Schapire, 1945, p. 111. McGrady no duda de que el romance "La bella malmaridada" es "el más glosado de la literatura española" e igualmente afirma que su origen tiene que buscarse en una copla o villancico. Mcgrady, Donald: “Otra vez el 'mal cazador' en el romancero hispánico”, en Actas del IX Congreso de la Asociación Internacional de Hispanistas. Sebastián Neumeister (ed.), Frankfurt, 1989, p. 84.

6 Habla Rodríguez Marín: “La Malmaridada. Se dice por una señora llamada Peralta, de pequeña edad y hentil dispusicion; la qual, por sus pecados, casó con hombre tan feble, viejo y de mala complission, que ella tiene harta de mala ventura." Rodríguez Marín Francisco: "Apéndice II". Viaje del Parnaso, Madrid, C. Bermejo (Ed.), 1935, p. 452.

7 Menéndez Pidal, Ramón: Romancero Hispánico. Tomo I y II, Madrid, Espasa-Calpe, 1968, pp. 331-332. 
y colectivo: el modelo francés y el español. Menéndez Pidal centró sus apreciaciones en la parte del adulterio y obvió el resto de estas composiciones. Esto le valió para decir que el tema se nacionaliza. Pero los poemas de malmaridada presentan un proceso completo: desde la situación matrimonial hasta la desunión. La infidelidad para Menéndez Pidal parece ser el móvil del romance; el único propósito, entonces, es el de descubrir la traición de la mujer y darle la muerte que -en sus propias palabras- "merecida tiene". Molesta que no indague en la condición de malcasada. Por una parte, parece que se nos quisiera conducir hacia un arquetipo único, un romance original e incontrovertible, un modelo petrificado. Las características de la poesía oral resienten este tipo de simplificación porque son composiciones que trascienden la barrera de la popularidad, penetran y son adoptadas por el pueblo como si fueran patrimonio colectivo, así los cantores tienen la potestad de alterarlas según los gustos regionales. Y su supervivencia depende precisamente de esto, de cómo se adapten, remocen y sirvan de medio para expresar emociones colectivas. No en balde Francisco Martínez Yanes en "Los desenlaces en el romance de Blanca Niña: tradición y originalidad" nos presenta una variopinta selección de finales que van desde el castigo-muerte hasta una edulcorada separación de la pareja. ${ }^{8}$ Por otra parte, ni Menéndez Pidal ni Entwistle parecen percatarse de algo que ellos mismos han apuntado: los romances novelescos tienen que verse como depositarios de herencias poéticas porque "son hijos de otra escuela romancística más ligada a las tradiciones literarias, escuela dependiente en gran parte de las baladas extranjeras". ${ }^{9}$ Fijémonos que al hablar de los romances de malmaridada inmediatamente surgen otras composiciones literarias. Lo que nos lleva a abrir el espectro de relaciones de los romances y socavar los giros y palabras que nos exponen. Ejercicio que investigadores como Paloma Díaz-Mas y Bárbara Salas García, entre otros, han dado en llamar indicios o fórmulas indiciales. ${ }^{10}$ Lo cual tiene mucho que ver con códigos (palabras claves) que se cuelan y permanecen ya sean entendidas o no (en su función de lenguaje otro) por los transmisores. Un lenguaje subrepticio que era apreciado por los poetas cultos de la Edad Media, pero que con el transcurrir de los años ha quedado olvidado.

Lo primero que salta a la vista en este tipo de romances es el nombre de la malmaridada: "Alba", "Blanca niña", "Rosa Blanca". ${ }^{13}$ Imágenes que refieren lo lumínico, la claridad incipiente y sin mácula. Nos trae a la imaginación algo que no se ha desarrollado

\footnotetext{
8 Incluso afirma que Entwistle no desconocía “que entre los textos que [...] manejó había no pocos que denunciaban claramente un esfuerzo por concluir el poema de forma más humana, si bien respetando la fundamental seriedad del tema." Véase Martínez Yanes, Francisco: "Los desenlaces en el romance de Blanca niña: tradición y originalidad", en El romancero hoy: poética. Catalán, Armistead y Sánchez Romerazo (eds), Madrid, 1979, p. 134.

9 Menéndez Pidal, Ramón: Romancero Hispánico Tomo I, Madrid, Espasa-Calpe, 1968, p. 160.

10 Díaz-Mas, Paloma: Romancero, Barcelona, Crítica, 1994, pp. 26-27; Salas García, Bárbara: "Un análisis del Romancero Erótico-Burlesco de la Provincia de Cádiz”, Lemir Revista Electrónica sobre Literatura Española Medieval y Renacimiento, Número 6 (2002): p. 5.30 de octubre de 2006. http://parnaseo.uv.es/Lemir/ Revista/Revista6/salas_cadiz.htm.

11 Timoneda, Juan de: Rosas de romances, Valencia, Editorial Castalia, 1963, pp. xxiiij-xxv.

12 Díaz Roig, Mercedes: El Romancero Viejo, Madrid, Cátedra, 1977, p. 263.

13 Bénichou, Paul: Romancero judeo-español de Marruecos, Madrid, Editorial Castalia, 1968, p. 142.
} 
del todo, que es joven, y que tal vez por esto no ha sido corrompido. Podríamos sospechar que el nombre no designa únicamente a la muchacha, nombra a ésta en tanto que posee las cualidades que refieren Alba, Blanca (juventud, claridad, sin mácula). Nuestro juicio parecería arbitrario si no lo respaldáramos. El Romance de Albertos nos trae estos versos: "Que es lo que teneys señora mudada estays de color: / perdiste alguna joya? o teneys zelado amor?"14 Las intervenciones son del marido. Las profiere después de que ha llegado al hogar y ha encontrado a su esposa en una actitud inusual. Fijémonos que la respuesta a la primera pregunta es algo extraña: "Mudada estays de color". La Edad Media tenía una forma particular de decir las cosas. Podríamos pensar que la mujer se sorprendió, se sonrojó, y esto fue percibido por su marido. Pero sería una respuesta bastante ingenua, poco poética además y desconocedora de un motivo que se repite constantemente en diversos romances de esta tradición, ${ }^{15}$ donde el cambio de color siempre está asociado con el asunto amoroso. El mismo marido atribuye a lo erótico las mutaciones sufridas por su mujer, lo que se resume en los versos ya citados: "perdiste alguna joya? / o teneys zelado amor?" Singular transformación sólo se produce después del acercamiento del amante, quien ha socavado su estado de blancura y pureza previo. Los nombres dados a las protagonistas no parecen nada casuales; responderían a una intención determinada: reflejar el estado virginal de la mujer.

Juan Victorio fue, creo, el primero en hablar de esta rara mutación. Estudiando la lírica tradicional afirma que el sol llena la poesía de "morenicas", mensaje profundo que de ser entendido literalmente nos permitiría contar una "bobada": una mujer se broncea por el sol; pero que si es entendido simbólicamente daría a conocer que las jóvenes no quieren protegerse con cremas protectoras sino disfrutar de su cuerpo a cabalidad:

Esta proliferación de "morenas" explicaría, o al menos no se opondría, la fama que en la literatura medieval tenían las rubias de tez blanca y ojos azules, que simbolizarían la blancura ya vista, es decir la virginidad, la cual concuerda muy bien con doncellas encerradas en su castillo y aprisionadas en su virtud. Porque las morenas (de las coplas), llegado el momento, empezarían a gozar de cierta reputación:
¿Cómo quieres, morena, amor constante, si tú de las mujeres, eres la más mudable? ${ }^{16}$

Afirmar que las muchachas de los romances hayan sido tostadas por el sol es bastante ingenuo, como apunta Victorio. No resultaría arriesgado sostener que el cambio de color

\footnotetext{
14 Timoneda, Juan de: Rosas de romances, Valencia:, Editorial Castalia, 1963, pp. xxiiij-xxv.

15 Para ejemplos véase Alvar, Manuel: Romancero Viejo y Tradicional, México, Editorial Porrúa, 1987, pp. 268-71. No dudo que esto aparezca en obras medievales de otro género. En Tristán e Isolda de Godofredo de Estrasburgo, por ejemplo, la madre de Tristán se llama Blancaflor, aunque ciertamente su estado virginal se pierde, no se juega con el cambio de color de la mujer

16 Victorio, Juan: El amor y su expresión poética en la lírica tradicional, Madrid, Editorial J. García Verdugo, 1995, pp. 92-93.
} 
representa la pérdida de la virginidad. ${ }^{17}$ Así lo entiende el marido, quien responde su propia pregunta atribuyendo la mutación a la acción amorosa. Los nombres de las protagonistas también refieren juventud: alba es la primera luz del amanecer, y blanco connota lozanía, pureza: lo que está naciendo, desarrollándose, lo que no ha logrado su clímax. Si trasvasamos estas acepciones a la muchacha, tendríamos que afirmar que es muy joven, casi una niña. Una niña casada. Algunos romances quieren ser patentes en el asunto, por no decir alarmantes, como el de Celinos y la Adúltera, donde vemos a una jovencita casada con un viejo, mientras éste la requiere de amores, la niña añora sus juguetes: "La niña quere juguete / y el viejo quere folgar." 18

En La bella malmaridada el amante no entiende por qué el marido se encuentra lejos de su mujer, siendo ésta tan apetitosa al género masculino por ser linda y además virgen. Incluso en Blanca Niña y en el Romance de Albertos lanza una maldición fuerte al esposo por haber salido de montería mientras su mujer permanece sola en el hogar. El amante sí estará dispuesto a gozar de la dama. Es él quien franquea la virginidad, transforma a la protagonista, poéticamente la vuelve morena o negra. En algunos romances de malmaridada las mujeres no parecen inexpertas en los tratos amorosos, ${ }^{19}$ incluso en ocasiones tienen hijos. Esto nos obliga a comprender la virginidad desde un abanico de significación más amplio y no entenderla solamente desde el punto de vista literal. Volver morena a la mujer significa transformarla, contaminarla, establecer conexión emocional con ella. Aunque en algunos romances la mujer haya dado hijos a su esposo, no por esto deja de ser virgen emocionalmente ni está menos dispuesta a tener contacto con el amante, incluso, acepta escapar abandonando a los hijos. ${ }^{20}$ La pérdida de la virginidad algunas veces se da de forma literal, pero también puede ser entendida de forma simbólica, es decir, la mujer establece contacto emocional con lo masculino, logra contaminarse, mutar, transformarse; algo que siempre ocurre con los amantes y no con los esposos. La virginidad desde su concepción etimológica no tiene que ver con la pérdida del himen sino con un estado que no permite la unión con lo extraño, en este caso, lo masculino. Virgen, desde este punto de vista, no connota posesión de himen, refiere la carencia de hombre, el estado de doncellez. ${ }^{21} \mathrm{Y}$ tener

17 Es un motivo que se repite en otras obras. En el auto sacramental La locura por la honra de Lope de Vega, la mujer en cuestión, Blanca (el alma), se transforma en negra. En La bella malmaridada, también de Lope, Casandra, mujer de dudosa reputación, se llama a sí misma negra (I, 405). En Los malcasados de Valencia de Guillén de Castro se hace referencia a esta extraña mutación de color con connotaciones claramente sexuales. Hablan Eugenia y Elvira. La primera pierde el color por el esfuerzo físico de subir una escalera. La segunda relaciona la pérdida de color con la pérdida de la virginidad, la cual ha entregado a Don Álvaro y, a diferencia del aliento, es irrecuperable:

EUGENIA Lo que perdí a la subida de esta escalera he cobrado, que es el color.

ELVIRA Suerte ha sido... ¡Ay de mí, que no podré! (I, 650)

18 Alvar, Manuel: Romancero Viejo y Tradicional, México, Editorial Porrúa, 1987, p. 83.

19 Puede revisarse, por ejemplo, los romances de Mujer engañada y La amiga de Bernal Francés. Véase Alvar, Manuel: Romancero Viejo y Tradicional, México: Editorial Porrúa, 1987, p. 19; Menéndez Pidal, Ramón: Flor Nueva de Romances Viejos, Madrid, Espasa-Calpe, 1982, p. 123.

20 Bénichou, Paul: Romancero judeo-español de Marruecos, Madrid, Editorial Castalia, 1968, pp. 134 y 139.

21 Sobre las apreciaciones etimológicas y psicológicas de esta concepción véase Markale, Jean: El Amor Cortés o la pareja infernal, Barcelona, José J. de Olañeta Editor, 1998, pp. 203-231. 
hombre significa establecer contacto emocional con él y no simplemente llevar a cabo el acto carnal. Sólo con el amante la malmaridada puede cambiar su estado, de virgen a conocedora, contaminada, de lo masculino.

Otra cosa llama la atención del amante. Está armado y lleva caballo. Por esto el esposo nota su presencia:

Cuyas son aquellas armas que tienen tal resplandor?

Veras, que oy señor Albertos las limpie de esse tenor.

De quien es aquel cauallo que siento relinchador? ${ }^{22}$

Es decir, el amante desordena la casa. Ya ha desordenado el estado de pureza de la mujer. Ahora vemos que deja huellas por todas partes, las armas desperdigadas, el caballo a la vista. Como si casa y mujer fueran casi la misma cosa. Las dos sufren mutaciones y muestran las pruebas de éstas. Notable es que para entrar en la casa de la malmaridada no es necesario burlar candados, ni saltar tapias, la mujer, al igual que la casa, está abierta para que entre el amante, éste, con su palabra, franquea las puertas, tanto físicas (casa) como emocionales (mujer). El espacio del hogar se entiende así como una especie de álter ego de la esposa.

Las armas en esta época serían signo inequívoco de que el amante es un caballero armado. Algo que afirma Entwistle al hablar de las obras francesas de las que los romances de malmaridada son herederos. Esto refleja el modo de vida del amante, un caballero armado, un noble, cuya cotidianidad consiste en buscar lances de todo tipo. Las armas no se mencionan para aludir al hecho bélico. Se hace referencia a ellas para decir que son extrañas a la casa, que no pertenecen al recinto conyugal. Después de que entra el amante, la mujer posee un color que no le es propio. Ambas, casa y mujer, han cambiado luego de tener contacto con el amante. Las armas no refieren guerra, al menos no bélica, sino amorosa, tópico bastante difundido en la literatura occidental. Sólo servirán para enfrentamientos sexuales. Nuestros amantes están armados, es decir, son aptos para el amor carnal. ${ }^{23}$

Este uso de la palabra arma y sus derivados lo podemos ver en El Viejo Celoso, de Cervantes. El mozo que le consigue Hortigosa a Doña Lorenza, aunque es rico, éste no es su principal atractivo. Es joven, aspecto que añora Doña Lorenza, quien está casada con un viejo acomodado que no la satisface sexualmente. Y juventud en estas obras quiere decir estar armado para la guerra amorosa, a lo cual alude Cristinica, la precoz sobrina de Doña Lorenza, de una forma muy clara. Ante las aprehensiones de su tía de tomar amante mozo, le replica: "A fe, señora tía, que tiene poco ánimo, y que si yo fuera de su edad, que no me espantaran hombres armados". ${ }^{24} \mathrm{Y}$ el mozo no viene literalmente aparejado con instrumentos de guerra, de guerra bélica queremos decir, lo que apunta que armado debe entenderse en un sentido metafórico. No es de extrañar, entonces, que los romances de malmaridada

22 Timoneda, Juan de: Rosas de romances, Valencia, Editorial Castalia, 1963, p. xxiiij.

23 Lo que parece ser un motivo bastante difundido. Recuérdese que en el romance (de malmaridada) $L a$ Casada Infiel de García Lorca el hombre está armado literalmente, revólver, dedos-navajas, y simbólicamente, sexualidad avallasadora. En El médico de su honra de Calderón el Infante Enrique, el único capaz de provocar deseos eróticos en Doña Mencía, deja caer su daga en casa de ésta.

24 Cervantes, Miguel de: Entremeses, México, Editorial Concepto, 1980, p. 119. 
sean repetitivos en el asunto. Cuando los amantes llegan, en la casa comienzan a aparecer armas desperdigadas, es decir, el lugar se convierte en un campo de batalla, carnal, por supuesto. El caballo es otro elemento que, al igual que las armas, no es propio del hogar de la malmaridada y causa extrañeza, por lo tanto podría connotar también potencia viril, no presente en la casa hasta la llegada del caballero. Armas y caballo, más que elementos literales, refieren juventud, fogosidad, sensualidad.

Intuimos que al oponer dos formas de vida, entiéndase la del amante y la del marido, éste, a través de los recursos de reticencia, tan comunes en el Romancero, representa lo contrario que el caballero andante. Existe una lejanía física entre los casados, dada porque el esposo se encuentra de montería, lo que repercute en un distanciamiento psíquico, la protagonista continúa siendo virgen. La ausencia del esposo hasta cierto punto carece de sentido ya que tiene en su hogar a una mujer linda y virgen, y constituye un comportamiento que rompe con interdictos conocidos de la época. Ya nos decían el Arcipreste de Hita en su Libro de Buen Amor y el Arcipreste de Talavera en su Corbacho ${ }^{25}$ que no debían los esposos dejar mucho tiempo solas a sus esposas porque éstas podían develar su naturaleza (maligna). La Edad Media concebía a la mujer como digna hija de Eva y, por lo tanto, siempre sospechosa de antentar contra el honor del esposo.

Llama la atención que se nos diga que el marido está cazando y pocos versos más adelante aparezca de repente en el hogar, instantes después de consumado el acto amoroso. Si vemos la palabra caza desde un punto de vista literario, nos encontraremos con que tiene, más allá de su significado literal, otra acepción. ${ }^{26}$ Quizá uno de los romances del Conde Claros sea el más ilustrativo de los tipos de caza que pueden darse: la caza de mujeres ${ }^{27}$ y la caza de la transgresión. Basten algunos versos para demostrar la primera. Claros no puede descansar:

25 Revisar el poema de "Pitas Paya" en Ruiz, Juan: Libro de Buen Amor, Madrid, Espasa Calpe, 1964, p. 56. Para entender cómo el llevar los cuernos es, más allá de cosa de burla, la publicación de una deficiencia y una falta al deber matrimonial consúltese Peristiany, J. G: El concepto del honor en la sociedad mediterránea, Barcelona, Labor, 1968, p. 46.

26 Véase Devoto, Daniel: "El mal cazador", en Studia Philological Homenaje ofrecido a Dámaso Alonso, Madrid, Gredos, 1960, pp. 481-91; McGrady, Donald: “Otra vez el 'mal cazador' en el romancero hispánico”, en Actas del IX Congreso de la Asociación Internacional de Hispanistas. Sebastián Neumeister (ed.), Frankfurt,1989, pp. 543-51.

$27 \quad$ Caza en estos romances fue entendida por Menéndez Pidal y también por Juan Victorio como algo que aumentaba la condición viril del esposo. Menéndez Pidal, Ramón: Flor Nueva de Romances Viejos, Madrid, Espasa-Calpe, 1982, pp. 23-25; Victorio, Juan: El amor y su expresión poética en la lírica tradicional, Madrid, Editorial J. García Verdugo, 1995, pp. 46-48. Así, cuando se decía que el marido se hallaba de caza se quería significar que estaba a la búsqueda de otras mujeres: la caza de Cupido. Hacían del adulterio femenino una revancha. Sobre los romances que empiezan con el íncipit "A caza iba el caballero" y sus implicaciones, ver Devoto, Daniel: "El mal cazador", en Studia Philological Homenaje ofrecido a Dámaso Alonso, Madrid, Gredos, 1960, pp. 485-86. Para el tema del cazador y "el halcón perdido", revisar McGrady, Donald: "Otra vez el 'mal cazador' en el romancero hispánico", en Actas del IX Congreso de la Asociación Internacional de Hispanistas. Sebastián Neumeister (ed.), Frankfurt, 1989, p. 457. Lope sabía bastante de los romances de malmaridada, a juzgar por tres de sus obras que hacen clara referencia a estos poemas: La locura por la honra, La malcasada y La bella malmaridada. En ésta última comedia nos habla de cómo Lisbella se considera a sí misma un cazador (I, 727 y siguientes). Su intención es cazar a su marido, el cual se encuentra de juerga. Y es que el mismo término de malmaridada o malcasada y sus asuntos encuentran en el Siglo de Oro nuevos problemas y vías alternas de representación, si atendemos a obras como Los malcasados de Valencia de Guillén de Castro o La bella malmaridada de Lope. 


\author{
Porque amor de Claraniña \\ no le deja sosegar. \\ Cuando vino la mañana \\ que quería alborear, \\ salto diera de la cama \\ que parece un gavilán
}

La comparación con el gavilán, ave de presa, no es gratuita. Cuando puede hablar con Claraniña, se refuerzan las características cinegéticas. La infanta le dice que después de los baños estará lista para él. Pero, Claros, voraz, no la deja ir:
-Bien sabedes vos, señora,
que soy cazador real;
caza que tengo en la mano
nunca la puedo dejar.-
Tomarala por la mano,
y para un vergel se $\operatorname{van}^{28}$

También existe otro tipo de cazador. ${ }^{29}$ Se trata de un individuo externo, que no participa de los amores entre los jóvenes. Un personaje que aunque no atrapa ninguna presa (animal), sí descubre algo que trasgrede las normas sociales. En el Romance del Conde Claros se le llama cazador en cuatro ocasiones, ninguna de las cuales hace referencia a la literalidad del sustantivo:

Mas fortuna que es adversa

a placeres, y á pesar

trujo allí un cazador,

que no debia pasar,

detrás de una podenca,

que rabia debia matar.

Vido estar al conde Claros

con la infanta á lindo holgar.

El Conde cuando lo vido

empezóle de llamar.

-Ven acá tú, el cazador,

si Dios te guarde de mal

28 Durán, Agustín: Romancero General o Colección de Romances Castellanos, Madrid, Biblioteca de Autores Españoles, 1945, pp. 218- 219.

29 Sobre este tipo de cazador se puede consultar McGrady, Donald: “Otra vez el 'mal cazador' en el romancero hispánico”, en Actas del IX Congreso de la Asociación Internacional de Hispanistas. Sebastián Neumeister (ed.), Frankfurt, 1989, pp. 543-551. Allí se rastrea hasta el Cligés de Chrétien de Troyes las escenas de los halcones extraviados en obras como La Celestina, el Poema de Fernán González, entre otros. 


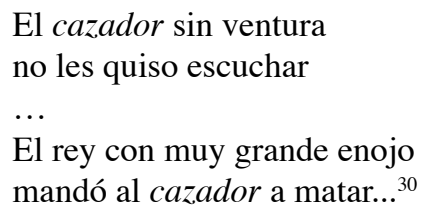

Según esta tradición podría aprehenderse la palabra caza en los romances de malmaridada. Así tendríamos un cazador (el amante) que caza (seduce) a la esposa. Y hay otro cazador (el marido) que los descubre. Ninguno realiza la acción de forma literal, ninguno caza animales. ${ }^{31}$

España dio a estos romances un final otro, diferente del original francés. Si bien es cierto que en algunos casos hizo de la malmaridada un asunto serio, no es menos cierto que no pudo desaparecer del todo la irrisión inicial contra el marido: burla áspera devino en algo velado y poético. Podemos inclinarnos a pensar que los romances primigenios medievales (si es que alguna vez existió algo que tenga la etiqueta de original en la oralidad) eran más condescendientes con la mujer, que paliaban la culpa del adulterio femenino con al exposición íntima de la situación matrimonial y que denunciaban, mejor, publicaban, una unión en gran parte asimétrica, al menos enrarecida. No nos atrevemos derivar conclusión moral de estas obras. Qué pensarían los hombres medievales de ellas es algo que roza el terreno de la especulación ${ }^{32}$, tampoco podríamos afirmar que, más allá de un reducida población culta, el vulgo llevara a cabo los procesos de analogía y relaciones hipo e hipertextuales que hemos presentado. A pesar de esto, los diferentes tópicos que exponen los poemas han sido conservados, quién sabe si inconscientemente, de boca en boca, de cantor en cantor. Lo que confirma una

30 Durán, Agustín: Romancero General o Colección de Romances Castellanos, Madrid, Biblioteca de Autores Españoles, 1945, p. 119.

31 No queremos dar un paso adelante sobre las connotaciones voyeuristas que esto implicaría; lo que cae en el terreno de la especulación. Pero tomando en cuenta que todos los episodios que relatamos podrían tener origen psíquico en un arquetipo bastante antiguo a saber: el de Hefestos-Afrodita-Ares, no sonaría extraño que la idea de voyeurismo estuviera presente. El médico de su honra, aunque no presenta ningún episodio concreto de voyeurismo, sí roza el tema: Gutierre, oculto, saltando las tapias de su propia casa, llega a los aposentos de su esposa, Mencía, con la intención de sorprenderla en amores con el infante Enrique. Asunto tópico que, según Avalle-Arce, provendría del romance de malmaridada Bernal Francés. Avalle-Arce, Juan Bautista: Temas Hispánicos Medievales, Madrid, Gredos, 1974. Por otra parte, Enrique se compara a sí mismo con Acteón, el desafortunado cazador que obtuvo la muerte por trasgredir con su voyeurismo los espacios sagrados de Artemisa:

Estas verdes hojas

me escondan y disimulen;

que no seré yo el primero

que a vuestras espaldas hurte

rayos al sol: Acteón

con Diana me disculpe.

32 Para saber algo más de lo que piesan actualmente los cantores y espectadores de estos poemas se puede consultar Anahory-Librowicz, Ana: "Las mujeres no castas en el romancero: un caso de honra", en Actas del IX Congreso de la Asociación Internacional de Hispanistas. Sebastián Neumeister (ed.), Frankfurt, 1989, p. 326; Salas García, Bárbara: "Un análisis del Romancero Erótico-Burlesco de la Provincia de Cádiz", Lemir Revista Electrónica sobre Literatura Española Medieval y Renacimiento, Número 6, (2002), p. 3, 30 de octubre de 2006. http://parnaseo.uv.es/Lemir/Revista/Revista6/salas_cadiz.htm. 
vez más que el Romancero posee mecanismos de autodefensa, una especie de sistema inmunológico que lo protege de la erosión del tiempo y las personas. Y es quizás en esta medida que se pueden llevar a cabo conclusiones. Lo importante prevalece a pesar o gracias al tamiz de lo popular.

\section{BIBLIOGRAFÍA}

ALCINA FRANCH, J.: Romancero Antiguo. Tomo II, Barcelona, Editorial Juventud, 1971.

ALVAR, M.: Romancero Viejo y Tradicional, México, Editorial Porrúa, 1987.

Poesía tradicional de los judíos españoles, México, Editorial Porrúa, 1987.

ANAHORY-LIBROWICZ, A.: "Las mujeres no castas en el romancero: un caso de honra", en Actas del IX Congreso de la Asociación Internacional de Hispanistas. Sebastián Neumeister (ed.), Frankfurt: Vervuert, 1989, pp. 321-330.

AVALLE-ARCE, J.: Temas Hispánicos Medievales, Madrid, Gredos, 1974.

BARBIERI, F. A.: Cancionero musical español de los siglos XV y XVI, Buenos Aires, Editorial Schapire, 1945.

BÉNICHOU, P.: Romancero judeo-español de Marruecos, Madrid, Editorial Castalia, 1968.

CALDERÓN DE LA BARCA, P.: No hay burlas con el amor / El médico de su Honra, Buenos Aires, Espasa Calpe, 1946.

Obras de Calderón de la Barca. Tomo VII, Madrid, Biblioteca de Autores Españoles, 1944.

CASTRO, G.: Obras Completas, Madrid: Fundación José Antonio de Castro, 1997.

CARLÉ, M.: La sociedad hispano medieval: sus estructuras, Buenos Aires, Gedisa Editorial, 1984.

CERVANTES, M.: Novelas Ejemplares Tomo II, Madrid, Espasa Calpe, 1996. Viaje del Parnaso, Madrid, C. Bermejo editor, 1935.

Entremeses, México, Editorial Concepto, 1980.

CID, J. A. : "Recolección moderna y teoría de la transmisión oral: El traidor Marquillos, cuatro siglos de vida latente", en El romancero hoy: nuevas fronteras. Sánchez Romeralo, Catalán y Armistead (eds.), Madrid: Gredos, 1979, pp. 281-359.

DEVOTO, D.: “El mal cazador”, en Studia Philological Homenaje ofrecido a Dámaso Alonso, Madrid, Gredos, 1960, pp. 481-91.

DÍAZ-MAS, P.: Romancero, Barcelona, Crítica, 1994.

DÍAZ ROIG, M.: El Romancero Viejo, Madrid, Cátedra, 1977.

DURÁN, A.: Romancero General o Colección de Romances Castellanos, Tomo I y II, Madrid, Biblioteca de Autores Españoles, 1945.

ENTWISTLE, W. J.: “Blanca Niña”, Revista de Filología Hispánica, I (1985). pp. 159-164.

GARCÍA LORCA, F.: Obras completas, Bilbao, Aguilar, 1968.

LABRADOR HERRAIZ, J. y R. DIFRANCO.: "Continuidad de la poesía del XV en canciones del XVI", Prologus Baenensis, No 1, pp. 1-52. 30 de octubre de 2006. http:// www.juanalfonsodebaena.org/ACTAS\%20LABRADOR.htm 
MARKALE, J.: El Amor Cortés o la pareja infernal, Barcelona, José J. de Olañeta Editor, 1998.

MARTÍNEZ DE TOLEDO, A.: El Corbacho, Madrid, Editorial Gráficas Torroba, 1970.

MARTÍNEZ YANES, F.: "Los desenlaces en el romance de Blanca niña: tradición y originalidad”, en El romancero hoy: poética. Catalán, Armistead y Sánchez Romerazo (eds.), Madrid, 1979, pp. 132-153.

MCGRADY, D.: “Otra vez el 'mal cazador' en el romancero hispánico", en Actas del IX Congreso de la Asociación Internacional de Hispanistas. Sebastián Neumeister (ed.), Frankfurt, 1989, pp. 543-551.

"Análisis de La bella malmaridada, de Lope", en Estudios sobre el Siglo de Oro: en homenaje a Raymond $R$ Ángel González, Tamara Holzarpfel y Alfred Rodríguez (eds.). MacCurdy, Madrid, 1983, pp. 83-91.

MENÉNDEZ PIDAL, R.: De primitiva lírica española y antigua épica, Madrid, EspasaCalpe, 1977.

Flor Nueva de Romances Viejos, Madrid, Espasa-Calpe, 1982.

Romancero Hispánico. Tomo I y II, Madrid, Espasa-Calpe, 1968.

Los Romances de América y otros estudios, Buenos Aires, Espasa-Calpe, 1958.

Cómo vive un romance, Madrid, Consejo Superior de Investigaciones Científicas, 1954.

PERISTIANY, J. G.: El concepto del honor en la sociedad mediterránea, Barcelona, Labor, 1968.

RODRÍGUEZ MARÍN, F.: “Apéndice II”, Viaje del Parnaso, Madrid, C. Bermejo Editor, 1935.

RUIZ, J.: Libro de Buen Amor, Madrid, Espasa-Calpe, 1964.

SALAS GARCÍA, B.: "Un análisis del Romancero Erótico-Burlesco de la Provincia de Cádiz”, Lemir Revista Electrónica sobre Literatura Española Medieval y Renacimiento, Número 6, pp. 1-15. 30 de octubre de 2006. http://parnaseo.uv.es/Lemir/Revista/ Revista6/salas_cadiz.htm

TIMONEDA, J.: Rosas de romances, Valencia, Editorial Castalia, 1963.

TROYES, CHRÉTIEN DE, Cligés, Madrid: Alianza, 1993.

VEGA CARPIO, L.: Comedias de Lope de Vega Carpio. Tomos II y VII, Madrid, Biblioteca de Autores Españoles, 1950.

VICTORIO, J.: El amor y su expresión poética en la lírica tradicional, Madrid, Editorial J. García Verdugo, 1995.

El amor y el erotismo en la literatura medieval, Madrid, Editora Nacional, 1983. 